\title{
Quantifying residualisation: the changing nature of social housing in the UK
}

Jen Pearce, Jim Vine

This is a pre-copyedited, author-produced version of an article accepted for publication in the Journal of Housing and the Built Environment following peer review.

The final publication is available at Springer via:

http://link.springer.com/article/10.1007/s10901-013-9372-3

http://dx.doi.org/10.1007/s10901-013-9372-3

The version of record may be cited as:

Pearce, J. \& Vine, J. J Hous and the Built Environ (2014) 29: 657.

doi:10.1007/s10901-013-9372-3

Over the last 40 years, social housing has become dominated by households on low incomes. However, there is a lack of recent research that quantifies residualisation, particularly the historical trends. This paper therefore presents an Index of Residualisation as a novel means of quantifying the changes. Using the Index, it is shown that, in 2010 social housing in the UK was three times more residualised than in 1970, but that residualisation has been broadly stable over the last 20 years. However, the UK government's social housing reforms are likely to change the tenure significantly and the impact of these changes on residualisation needs to be monitored. The Index is ideally suited to this role, and can also be used to investigate the drivers of residualisation and conduct comparative studies.

\section{Introduction}

It is generally agreed that UK social housing has undergone a long period of residualisation. Residualisation is a complex phenomenon and is the subject of considerable debate, but has been defined as "the process whereby public housing [and other social housing] moves towards a position in which it provides only a 'safety net' for those who for reasons of poverty, age or infirmity cannot obtain suitable accommodation in the private sector" (Malpass \& Murie, 1982, p. 174). The changes in the tenants that the sector houses and the 
role it plays have occurred over more than 60 years, and have resulted in the sector moving from a 'public housing' model, providing housing for a broad spectrum of households, to a 'social housing' model, housing only those unable to house themselves in the private market (Malpass \& Victory, 2010). Furthermore, the current UK government is introducing substantive reforms to social housing, which are likely to further impact the sector.

The aim of this research is to improve the understanding of these changes by analysing the shift in make-up of social housing tenants in terms of household income. While this is an area that was widely studied in the 1980s, recent quantitative analyses are more limited, and there is a lack of detailed analysis of long-term trends. After outlining the features of residualisation, the multiple and interlinking causes of the process are discussed. The subsequent sections of the paper focus on the quantification of residualisation, outlining previous literature and highlighting the need for a consistent measure of residualisation to enable analysis of trends and to aid comparative studies.

A new Index of Residualisation is then presented, which enables precise measurement of residualisation in terms of tenant incomes. The Index is then used to compare the extent of residualisation among different tenures in the UK over the last 40 years. Potential uses of the Index are then outlined, including use in comparative studies, examining the different social rented sectors across Europe, for example.

Residualisation comprises a range of features and influences, but at is heart is about a changing role for social housing. The original aim was that public housing would be a broad tenure, providing decent and affordable housing for the masses. Initially the focus was on the relatively affluent working classes, but provision soon expanded to provide for those on lower incomes. The vision was that public housing would cater for a wide cross-section of society:

"If we are to enable citizens to lead a full life ... they should all be drawn from different sections of the community. We should try to introduce what was always the lovely feature of English and Welsh villages, where the doctor, the grocer, the butcher and the farm labourer all lived in the same street ... the living tapestry of a mixed community" (Aneurin Bevan, quoted in Berube, 2005, pp. 2-3).

Public housing originally served households with a relatively wide range of incomes. By contrast, social housing is now increasingly seen as an "ambulance service" for those unable to support themselves (Harloe, 1978, p. 17). The current government has described social housing as giving "people the helping hand they need, when they need it" (DCLG, 2010). 
These trends can be observed in across Europe, with social housing "widely understood to be in retreat and on the defensive" (p. 3, Malpass and Victory, 2010). Residualisation is a complex and multi-faceted process, relating to the role of social housing, its provision and consumption. It is associated with a downgrading in status of the tenure and is linked to issues of social exclusion, stigma and quality (Forrest and Murie, 1983). To emphasise any one aspect of the process risks missing this complexity, but a number of common (although not necessary) features of residualisation can nonetheless be identified.

The key aspect of residualisation, as highlighted in the definition above, is the role that social housing plays in the wider housing system. It is this role and status that is reflected in a number of characteristics of the sector. Residualisation typically includes changing characteristics of social housing tenants: with rising levels of unemployment or economic inactivity and declining incomes in comparison with the population as a whole (Hills, 2007). Equally, a residualising sector is often in physical decline, both in terms of size and the quality of housing available (either through poor initial build quality, or failure to modernise housing as it ages; Clapham and MacLennan, 1983). In tenures governed by municipal or central government policy, residualisation is often reflected in policy decisions, for example restrictive allocations policies and declining state investment (Malpass, 1983).

Residualisation is also associated with less tangible issues of stigma and perceived quality. The issue is not solely one of practical changes, but a decline in how the tenure is viewed both by tenants and society as a whole (Forrest and Murie, 1983). This is of particular important because housing is related to "social position, reputation and stigma, access to services and to jobs, social cohesion at the neighbourhood level, and hence to life chances for the citizen" (Pawson \& Kintrea, 2002, p. 646), and therefore a residualising sector may increase social exclusion.

It should be noted at this point that although the literature around residualisation concentrates on social housing, it is not necessarily a tenure specific phenomenon. Any tenure could become residualised and any changes in one tenure will inherently affect other tenures. However, "it is in the council housing sector where these residualising forces find their most concentrated expression" (p. 464, Forrest and Murie, 1983).

\subsubsection{Modernisation}

These various interdependent aspects constitute the process of the residualisation of social housing, which has been described as a downgrading of the tenure (Forrest and Murie, 1983). However, this needs to be seen in the context of a wider process of modernisation (Malpass \& 
Victory, 2010). Residualisation has occurred alongside a wider restructuring of social housing, which has seen a shift in ownership from municipal authorities to a wider mix of providers, such as housing associations, and the greater use of private finance. There has also been greater emphasis on resident involvement and choice, with a move away from viewing tenants as passive welfare recipients to regarding them as empowered consumers. Equally, there has been considerable work to improve the quality of social housing stock through the Decent Homes Programme (National Audit Office 2010). The "discourse of decline" (p. 4, Malpass \& Victory, 2010) that has characterised the residualisation literature, is therefore too simplistic; the changes are part of a wider transition, not simply a downgrading.

\subsection{Causes of residualisation}

Residualisation has occurred through a wide range of interlinked influences, but broadly speaking the process has been driven by tenure restructuring, compounded by social and demographic factors, and supported by government policy.

\subsubsection{Tenure restructuring}

Since the start of the $20^{\text {th }}$ century, the tenure structure in the UK has changed dramatically (Figure 1). The social housing sector grew rapidly, particularly following the Second World War, while homeownership also expanded rapidly. Simultaneously, the private rented sector went into decline. These changes had a profound impact on social housing as it developed.

\section{FIGURE 1}




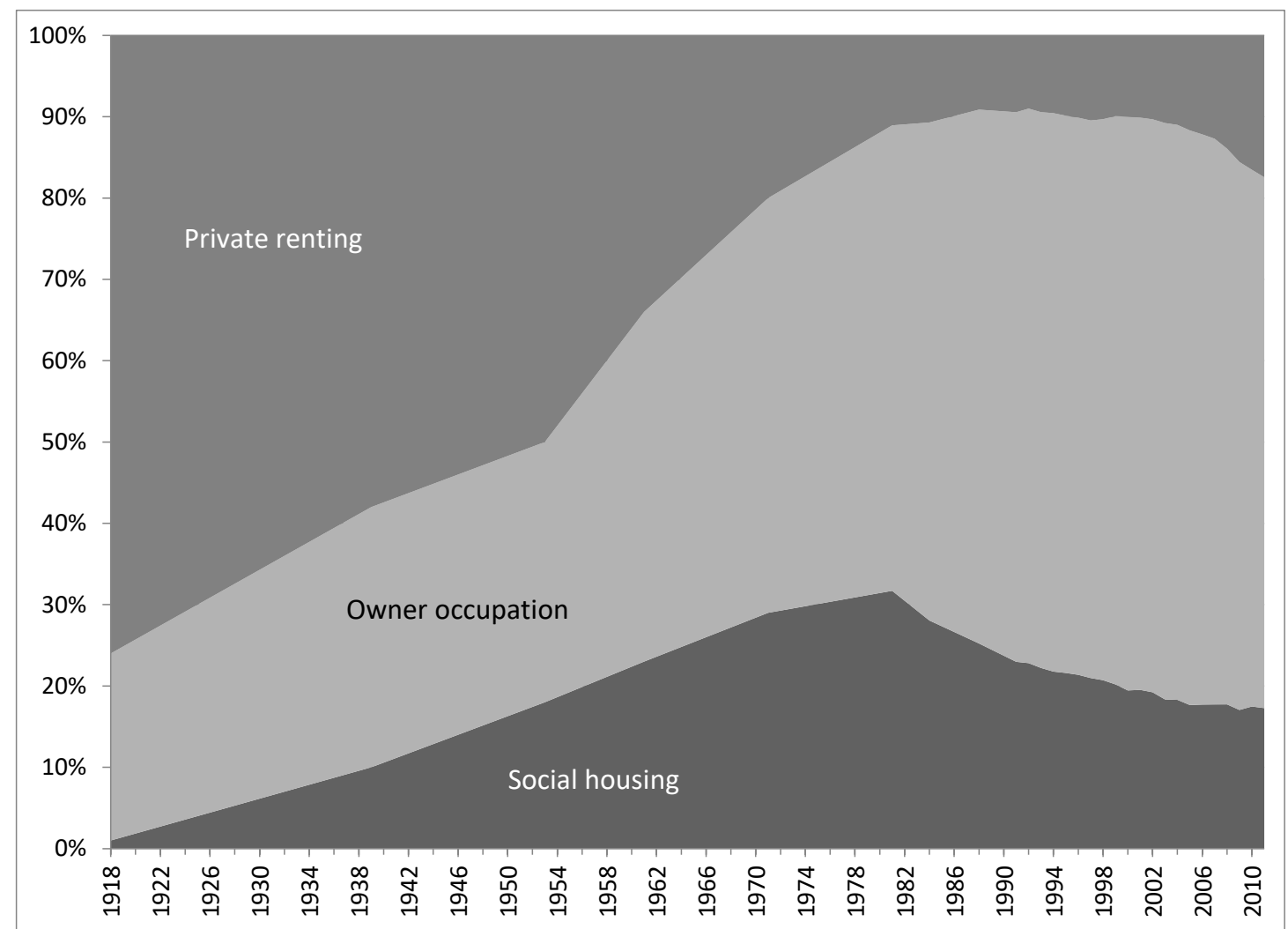

\section{Rise in homeownership}

In the earlier years of council housing, the sector was the tenure of choice for many working class households, providing as it did an affordable high quality home. However, as owner occupation became increasingly accessible to even affluent working class households (through the growth in mortgage availability and rising real incomes), homeownership became an important aspiration. Later on, rising house prices made owner occupation an attractive investment as well as a consumption good. These factors firmly secured homeownership as the tenure of choice for a significant proportion of society.

Social housing has therefore become only for those unable to take advantage of these benefits. In fact Malpass and Victory (2010) argue that as access to and aspiration for homeownership have grown alongside public housing from the start, social housing has always been, to some extent, a residual sector, in that it provided for those unable to effectively access the private market.

\section{Decline in private renting}

Alongside the growth in homeownership, the private rented sector declined rapidly until the late 1980s, in part due to strict rent controls, which made private landlordism an unattractive investment. Equally, there was a significant reduction in demand: as homeownership became increasingly accessible, people opted to buy rather than rent. Furthermore, there were 
programmes of slum clearance particularly during the 1960s to eradicate the worst private rented housing. In addition to its declining size, the sector was also relatively inaccessible, as high security of tenure meant that turnover in the sector was very low (Murie, 2009). These factors combined to reduce the capacity of the sector to house lower income households. This role then fell increasingly to the social rented sector (Murie, 2009).

However, in recent years the private rented sector has flourished in a climate of deregulation and affordability problems preventing many people accessing homeownership. The buy to let boom saw a massive growth in supply, which has been met by demand from those unable to access either owner occupation or social housing due to various constraints.

\subsubsection{Social and economic factors}

Forrest and Murie (1983) also point out that much of the change in household incomes and employment statuses is linked to labour market restructuring. The collapse of traditional manufacturing industries has disproportionately impacted social housing tenants who were far more likely to have been employed by these industries. These workers have found themselves unemployed with far fewer job prospects locally and a skill set that does not match the needs of the modern economy.

\subsubsection{Role of government}

In addition to these wider structural factors, residualisation has been compounded by government policy. However it is important to recognise that these policies were not sufficient to fundamentally shape housing tenures, but nonetheless interact. Some theories of residualisation "grossly [overrate] the power of the state to transform the situation of consumers" (Malpass, 1990, p. 26)

\section{Wider context of welfare}

Housing has been described as the wobbly pillar of the welfare state (Torgersen, 1987), never having had the same legitimacy or status as the NHS or education. This arises because housing is viewed more as a commodity than a social right and therefore market approaches have typically been favoured (Murie, 1997). Even from the outset, the move towards public housing provision was the result of a reluctant acknowledgement that the private sector was unable to meet housing need, rather than a particular favouring of public housing per se (Burnett, 1986).

This situation was exacerbated in the 1970s, with a growing shift towards a residual model of welfare, which views the market and the family as the main providers, with the state 
intervening only to support those unable to access support from these sources. This was driven in part by concerns regarding fiscal spending and subsequent retrenchment in public expenditure (Flynn, 1988) and has led to an emphasis on individual subsidies (e.g. Housing Benefit) rather than direct provision of housing (Cole \& Furbey, 1994).

\section{Incentivising homeownership}

This approach to housing and welfare has also demonstrated itself in the promotion by successive governments of homeownership as the tenure of choice and aspiration, at the expense of social housing. It has been actively incentivised through a variety of government schemes and fiscal incentives (Flynn, 1988). Tax advantages - particularly the abolition of the Schedule A tax on imputed rented in 1963 - given to homeowners amount to a subsidy comparable in size to Housing Benefit expenditure (Diacon et al., 2010).

Social housing tenants have also directly been incentivised to become homeowners through the Right to Buy. Giving tenants the right to purchase their council house at a substantial discount enabled many tenants to enter homeownership: in the first five years of the legislation, 460,000 properties (ten per cent of local authority stock) were sold in England (DCLG, 2013b). Right to Buy sales declined from the early 1990s, but by 2008, one third of social housing had been sold to former tenants (Murie, 2008). Those able to purchase their properties were typically better-off tenants, so those left in the sector were increasingly from the lower income groups (Forrest \& Murie, 1988).

\section{Reduced investment in social housing}

At the same time, social housing investment and provision have exhibited downward trends. In 2009, construction of social housing in the UK was only 13 per cent of its 1954 peak and 30 per cent of the level when the Right to Buy was introduced (DCLG, 2013a). The coalition government has also reduced the affordable housing grant from $£ 8.4 \mathrm{bn}$ for the period 200811, to $£ 4.5 \mathrm{bn}$ for the period 2011-15 (HCA, n.d.), with the aim of maintaining the level of provision, but at reduced grant per unit, with the remainder made up through increased rents. These more recent reductions are reflective of longer-term declines in subsidy.

The combination of reduced provision, sales (including the Right to Buy) and demolitions has led to a significant decline in the size of the sector. In 1981, over 30 per cent of households (5.5 million) lived in public housing; but by 2010 housed only 17 per cent of households (3.8 million; DCLG, 2011a).

\section{Allocations policies}


Furthermore, allocation policies have prioritised the poorest and most vulnerable tenants in granting tenancies. Needs-based allocation of social housing first came to prominence in the 1969 Cullingworth Report and quickly became accepted as good practice (Mullins \& Murie, 2006). Prior to this, allocation prioritised "skilled workers needed by industry and others whose rehousing would benefit the community" (p. 647 Pawson \& Kintrea, 2002). In addition to directly restricting access for better-off households, it has been argued that allocations policies also contribute to residualisation as they make applying for social housing a last resort, as applicants are only "those desperate enough to throw themselves onto the mercy of public bureaucracy" (p. 659, Pawson \& Kintrea, 2002).

\section{Quantifying residualisation}

Given the complexities of residualisation, a means of calibrating the process would be useful. However, the multi-dimensional nature of residualisation makes quantification problematic. To engage in quantification, it is therefore necessary to identify individual features (or a combination of a few features) that lend themselves to numerical analysis. Different approaches have been adopted in the literature, but the dominant approach has been to examine the characteristics of tenants. This is not to suggest that residualisation is simply about changing tenant characteristics, but rather that this is a useful indicator, as it is strongly associated with the process as a whole.

A study of Census data from 1961-1981 reveals significant changes in the socio-economic group of social tenants (Hamnett, 1984 ${ }^{1}$ ). The proportion of professionals, employers and managers in social housing remained constant, despite an overall increase across the population; conversely, the proportion of semi-skilled and unskilled workers in social housing increased by 30 per cent and 44 per cent respectively.

However, the use of both Census data and socio-economic group to measure residualisation has been criticised by Bentham $\left(1986^{1}\right)$. Census data is collected every ten years and so cannot provide a detailed picture of change and data will be ten years old by the time the next update is possible. Socio-economic group is also increasingly unhelpful in understanding residualisation as only the head of household is considered: the increase in multiple-earner households and retired heads of households means socio-economic group does not necessarily reflect the circumstances of the household. The change in the classification system of socioeconomic group further complicates the possibility of time-series analysis. 
Instead, Bentham (1986) used Family Expenditure Survey data to measure the change in income of households from 1953 to 1983: over this period there was an increase of nearly 140 per cent in the proportion of households in social housing drawn from the lowest income quartile and a 66 per cent decrease in the proportion of households drawn from the highest quartile. Residualisation has also been quantified by the number of households in receipt of welfare benefits. Between 1967 and 1984 the percentage of supplementary benefit recipients living in social housing rose from 45 per cent to 61 per cent (Forrest \& Murie, 1983).

More recently, analysis of Labour Force Survey data from 1981 and 2006 revealed that while in 1981, 67 per cent of working age householders in social housing were in full-time work, by 2006 this figure had halved to 34 per cent (Hills, 2007). There was also a five-fold increase in economic inactivity in social housing due to permanent sickness or disablement: from five per cent in 1981 to 25 per cent in 2006. Lupton et al. (2009) also quantified residualisation through the creation of an Index of Advantage, which assessed the effect on children's outcomes of living in social housing over four cohorts born between 1946 and 2000. In the earliest cohort, children living in social housing were from a range of backgrounds, with 11 per cent from the most advantaged group and 27 per cent from the least advantaged. By 2000 , only two per cent were from the most advantaged group and 49 per cent were from the least advantaged.

These studies provide strong evidence of residualisation and go some way to showing the extent of those changes. However, there is a lack of detailed quantification of residualisation particularly in more recent years and a limited understanding of the course and magnitude of the changes. The aim of this paper is therefore to provide precise quantification the course of residualisation over the last 40 years. In particular we present a new Index of Residualisation, which enables the precise comparison over different years, tenures and geographies. Of the approaches used in the literature, the Index uses household income as its primary measure because it is simple, widely available and most readily supports comparisons over time and national contexts. It also allows for a nuanced analysis, as the data are relatively continuous, in comparison with making a discrete distinction between a limited number of categories (e.g. employed, unemployed and economically inactive). Importantly, it is the least susceptible of the measures to the distorting effects of government policies. As highlighted above, socioeconomic categories can change, either making comparisons impossible, or creating artificial changes that do not reflect the underlying reality. Equally, changes to eligibility for benefit or different benefit systems between countries limit the possibility of comparisons. 


\section{Index of Residualisation}

The Index of Residualisation compares the incomes of those living in a particular tenure with the incomes of the population as a whole. If a particular tenure houses disproportionately more households with lower incomes, this indicates residualisation.

The Index is based on the Suits index of tax progressivity (Suits, 1977), which is in turn derived from the Gini coefficient. The Gini coefficient is a well-established measure of inequality, which measures the distribution of incomes within a population using a cumulative frequency distribution (Figure 2). In a population with total income equality (i.e. all households having the same income), the graph will resemble straight line OB. In a population where some households have a greater income than others, the graph curves below line OB and will resemble OCB. The Gini coefficient is the ratio between the area under the curve for a given population and the area given total income equality.

\section{FIGURE 2}

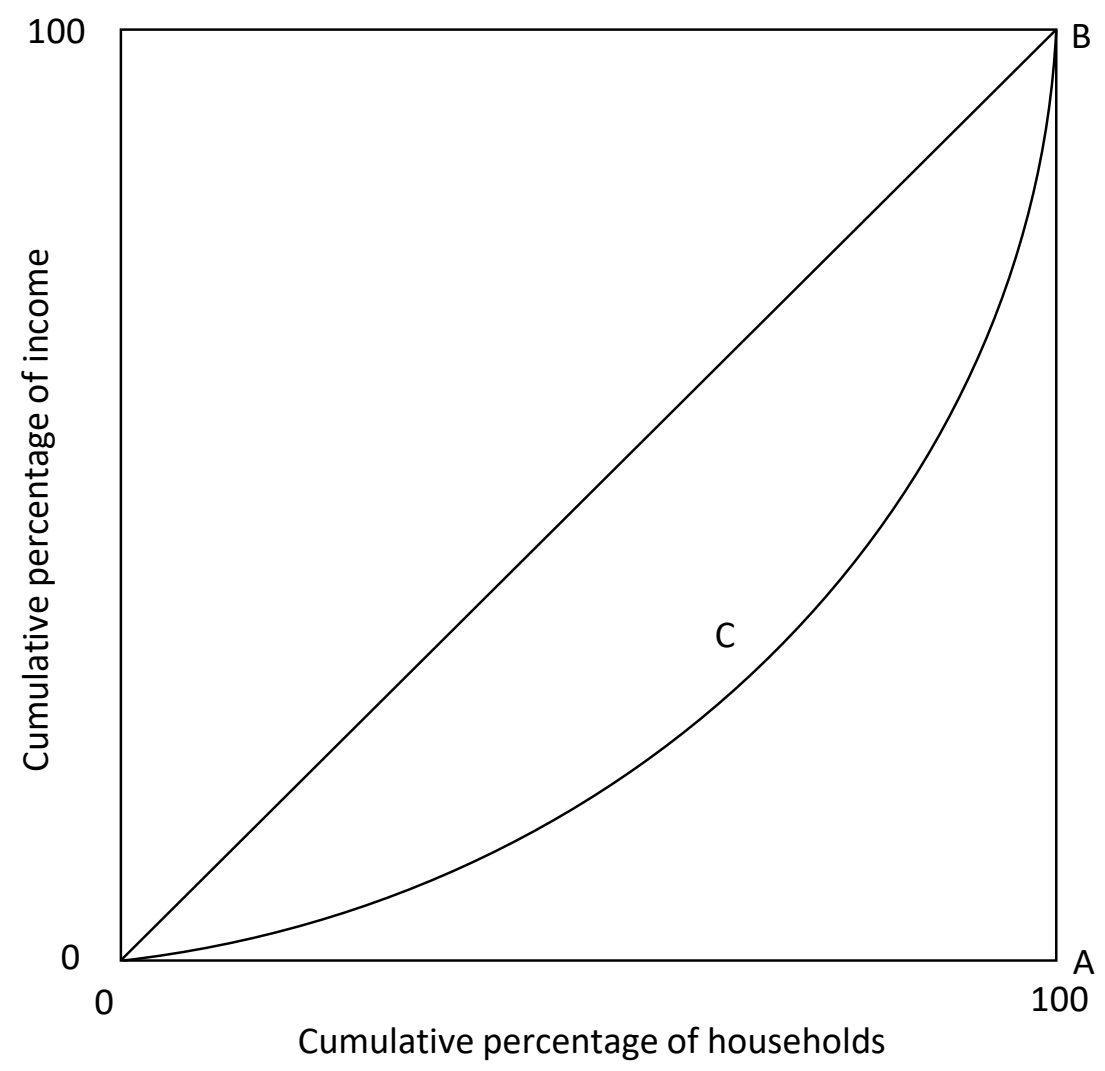

The Suits Index uses a similar principle to measure the distributional effects of taxation, by comparing the percentage of income received by households with the proportion of the tax burden paid (Figure 3). Straight line OB represents a tax that is paid proportionally by all 
households, regardless of income (e.g. a flat rate income tax with no lower income threshold). Line OCB is an example of a progressive tax, one for which the tax burden is borne more by wealthier households (e.g. many property taxes).

\section{FIGURE 3}

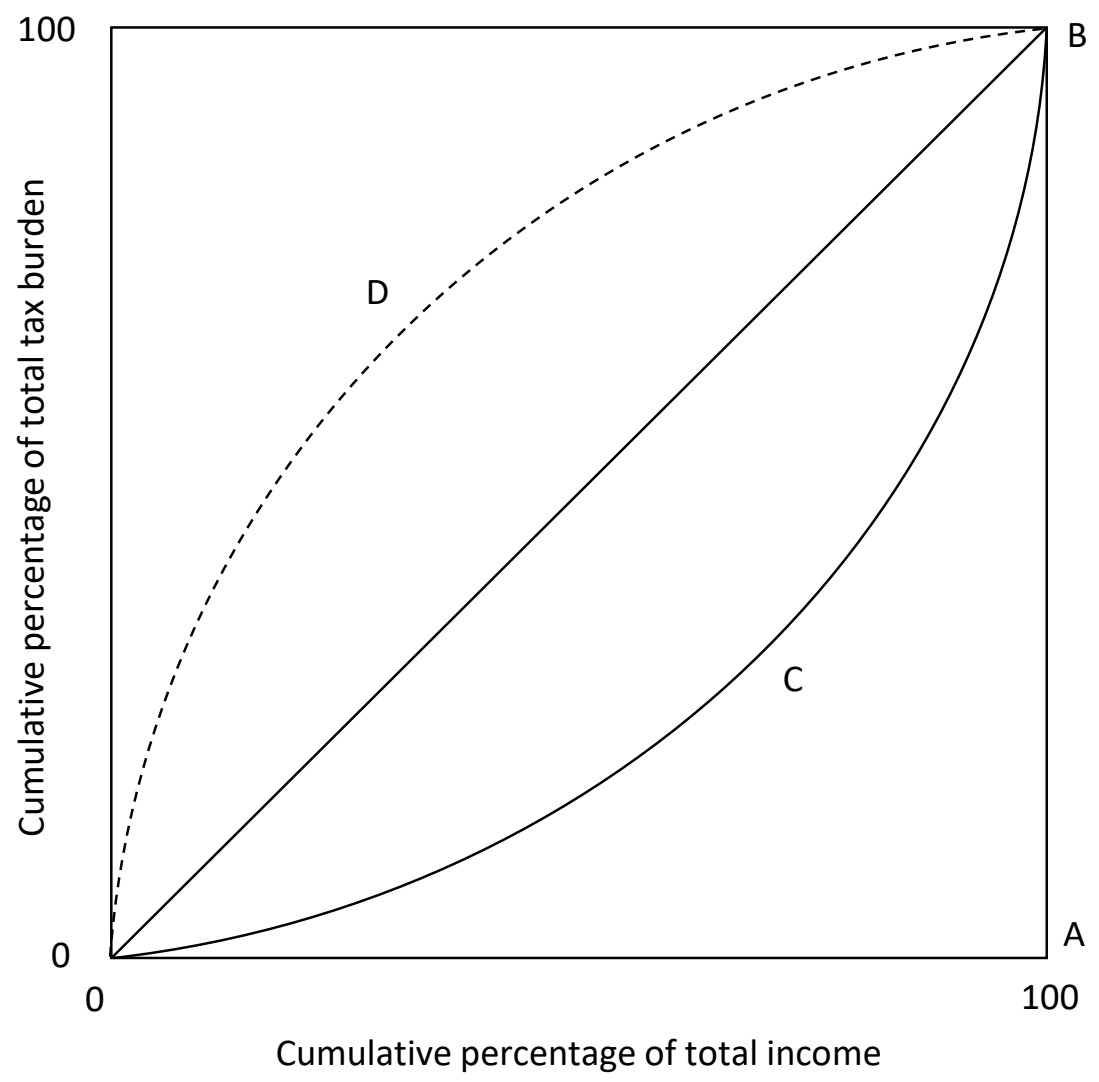

The key difference between the Suits Index and the Gini coefficient is that curves can go above the line of proportionality. This occurs when the tax burden falls more heavily on poorer households. Line ODB is an example of a regressive tax (e.g. a sales and excise tax). Like the Gini coefficient, the Suits Index calculates the ratio between the area under the curve and the area given proportionality.

The Index of Residualisation takes the structure of these well-established indices and applies them to the income distribution of households within a tenure in comparison with the wider population. For any household income, we can ascertain the proportion of households in a population and sub-population that have an income below this amount. By plotting these values against each other we can compare the income distributions of populations and subpopulations (Figure 4). When the income distribution of the sub-population is equivalent to that of the whole population, the graph forms straight line $O B$. If the sub-population is predominantly of a lower income, then the line will resemble $O C B$; if the sub-population is 
predominantly of a higher income, then the line will resemble $O D B$. The Index is then calculated by measuring the ratio between the area under the curve for a sub-population and area $O A B$.

\section{FIGURE 4}

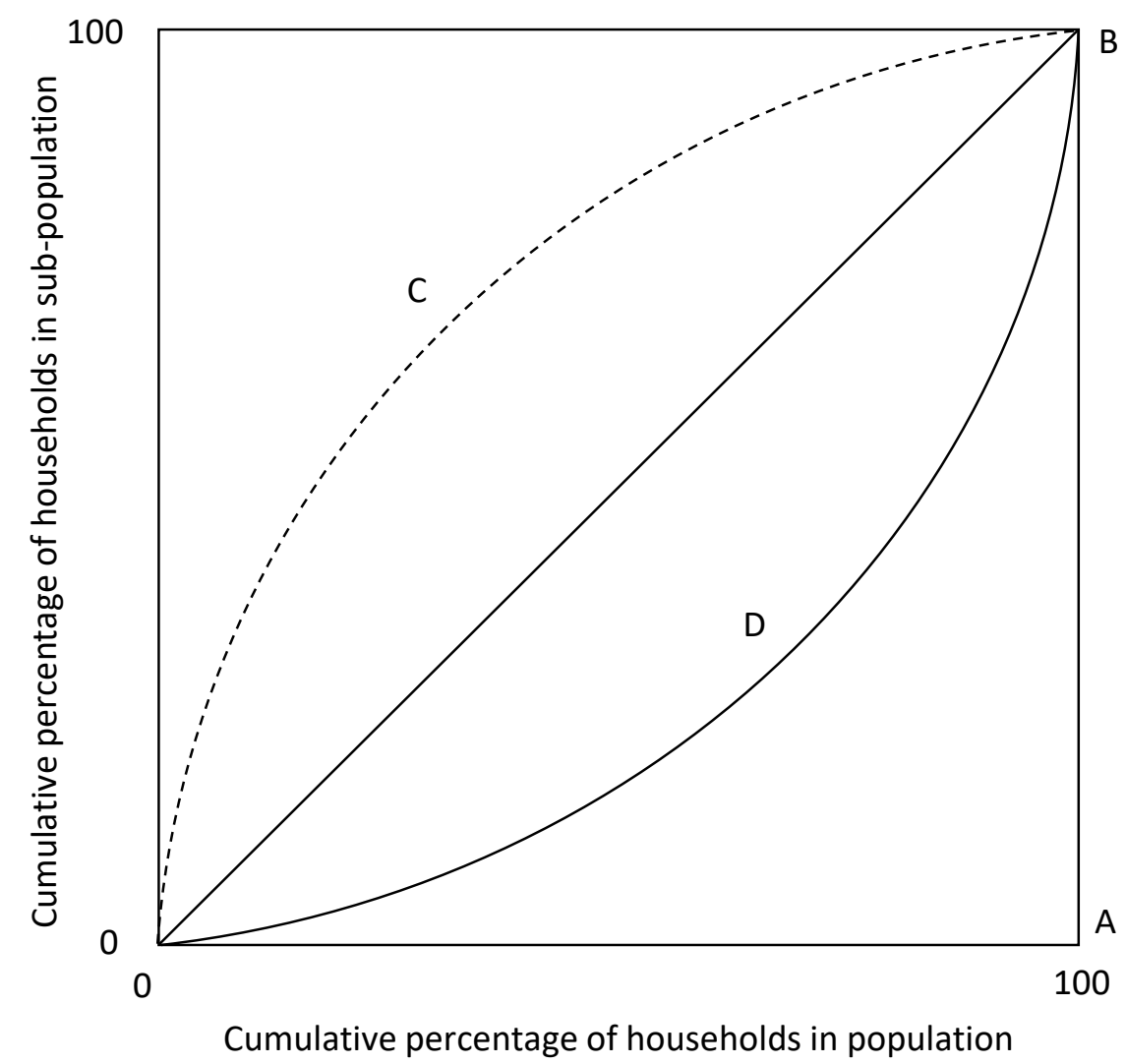

\subsection{Calculation}

The area under the curve for any given sub-population can be calculated as follows:

$$
L_{s}=\int_{0}^{100} F_{S}(p) d p
$$

where $p$ is the percentage of households in the population, $s$ is the percentage of households in the sub-population and $F$ is the function of the curve. To calculate the Index of Residualisation, the following formula is used.

$$
R_{s}=\frac{L_{s}}{K}-1
$$

$K$ is the area under the curve in a situation of proportionality $(O A B)$. 
In this general case, the variables are continuous and a formula is given for the curve.

However, in practice only discrete values will be known, and calculations can be completed by dividing population incomes into bands such as deciles or percentiles. In this analysis, household income was split into population deciles. In this case, the equation approximates as follows:

$$
L_{s} \approx \sum_{i=1}^{10} \frac{1}{2}\left[F_{s}\left(p_{i}\right)+F_{s}\left(p_{i-1}\right)\right]\left(p_{i}-p_{i-1}\right)
$$

where $p_{i}$ is the proportion of households in the population at or below point $p_{i}$ and $F_{s}\left(p_{i}\right)$ is the proportion of households in the sub-population (or tenure) at or below point $p_{i}$.

\section{Residualisation in the UK}

Having developed the Index, we then used it to analyse the changes in residualisation of social housing in comparison with the other tenures in the UK over the last 40 years.

\subsection{Method}

The data source selected was the Family Expenditure Survey and its subsequent forms (ONS, 2013a, 2013b, 2013c). The survey contains tenure and income data over 40 years, allowing long-term trends to be analysed. This is important because there has been evidence of residualisation as early as the 1950s (Bentham, 1986; Clapham, 2005). Although the dataset does not allow for the study of the earliest stages of residualisation, it covers key changes, such as the introduction of the Right to Buy. Between 1970 and 2010, an average of 7,000 households took part in the surveys annually.

From the survey, the main tenures (owner occupation (mortgaged and outright), social housing and private renting) were compared, with the income variable being average gross weekly household income. This was equivalised on the basis of household composition using the OECD modified scale ${ }^{1}$ to account for changing household composition and differences in household composition between tenures.

\subsection{Results}

In 1970, social housing tenants were drawn from across the income spectrum, with only a slight preponderance of lower incomes households (Figure 5; although deciles were used in

\footnotetext{
${ }^{1}$ For this scale, the first adult in a household counts as one unit, each subsequent adult as 0.5 and each child (under 15) as 0.3 units. The FES data counted those under 16 as children, so the equivalence calculations are not completely accurate, but are likely to be representative.
} 
calculations, quintiles are shown in the graphs for clarity). Around ten per cent of households in social housing were from the wealthiest fifth of the population. By 2010, half of social housing tenants were from the poorest fifth of the population and less than two per cent from the wealthiest fifth. Residualisation is evident from the start of the dataset studied, with an increasing preponderance of lower income households from 1970 onwards. This accelerated in the early 1980s, reaching a peak in 1991, with over half of households in social housing being drawn from the poorest fifth. After this peak, the level of residualisation has plateaued.

\section{FIGURE 5}

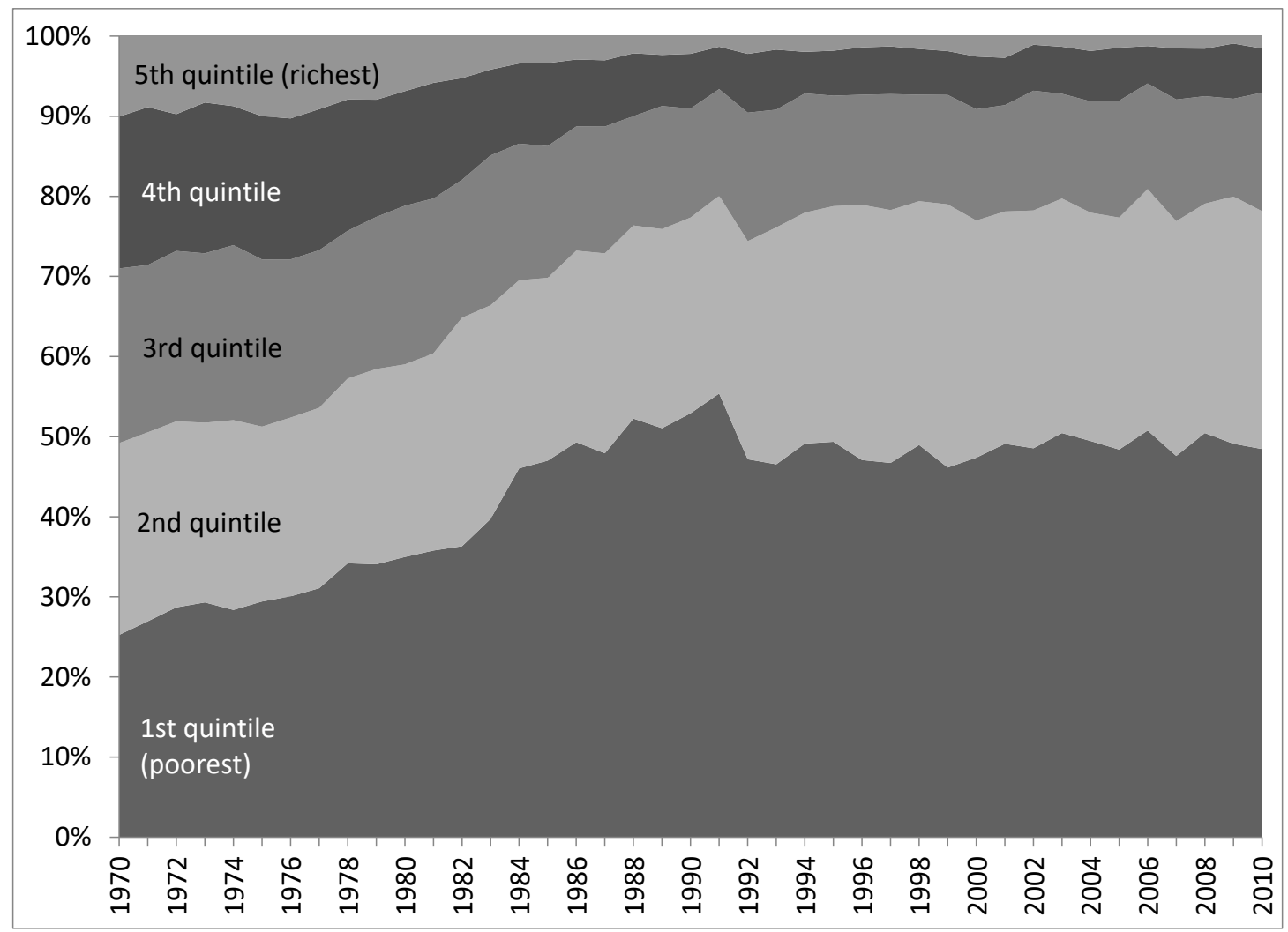

These changes in social housing can be compared with changes that occurred in the other tenures over the period. The income profile of owner occupiers remained fairly constant, averaging ten per cent of households from the poorest fifth of the population, 22 per cent from the middle fifth and 28 per cent from the richest fifth (Figure 6).

\section{FIGURE 6}




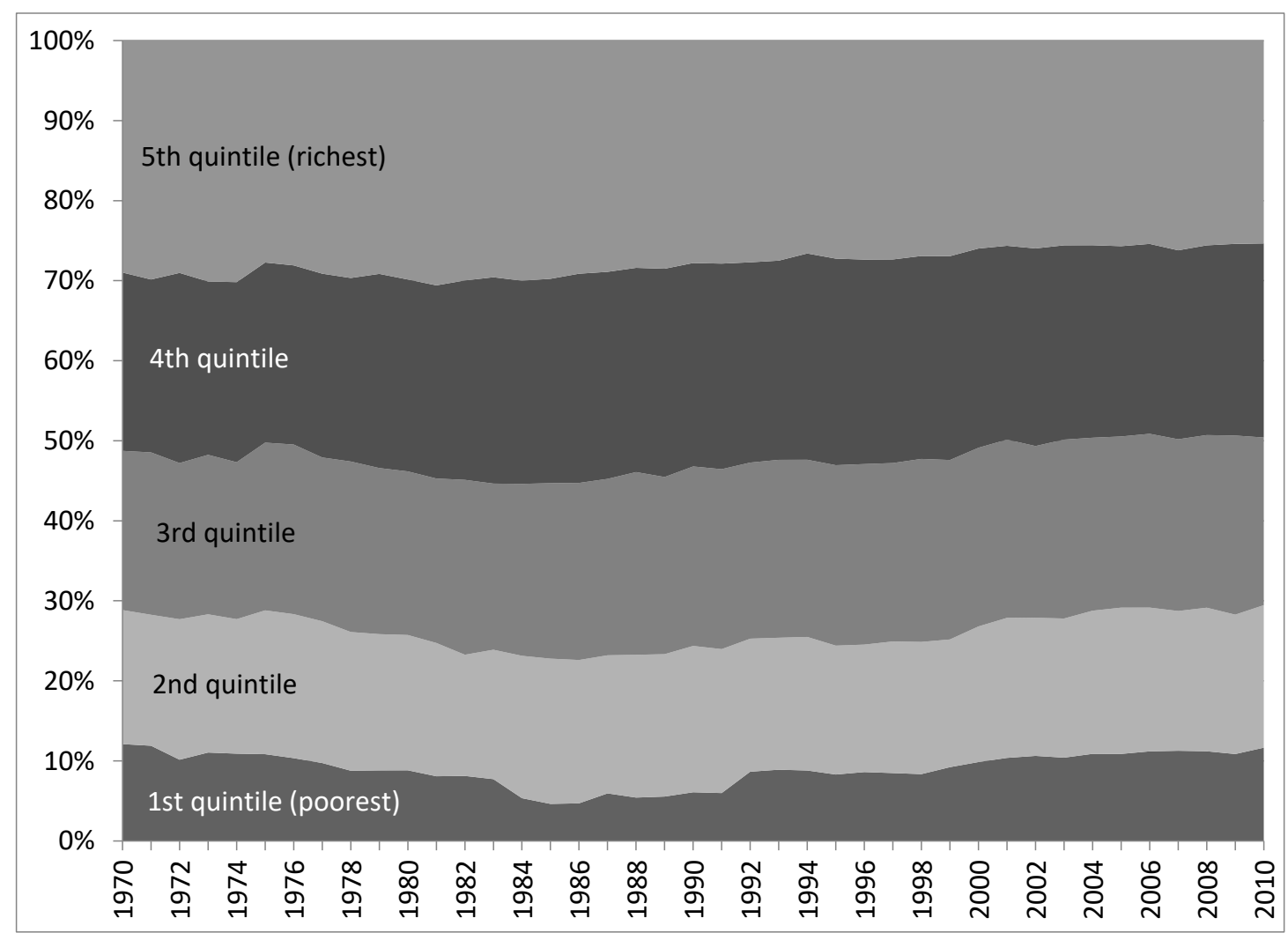

Given the large size of the owner-occupied sector (accounting for between 51 and 71 per cent of households across the period studied) it is instructive to separate out mortgaged and outright owners (Figures 7 and 8 respectively). Mortgaged owner occupiers have significantly higher incomes than outright owners (reflecting the fact that many outright owners will be retired). However, the low housing costs associated with outright ownership will mitigate lower incomes. Mortgaged owner occupiers have by far the highest incomes of any tenure, with 60 per cent of households in the top 40 per cent of earners, a figure that has stayed fairly constant since the late 1970s.

\section{FIGURE 7}




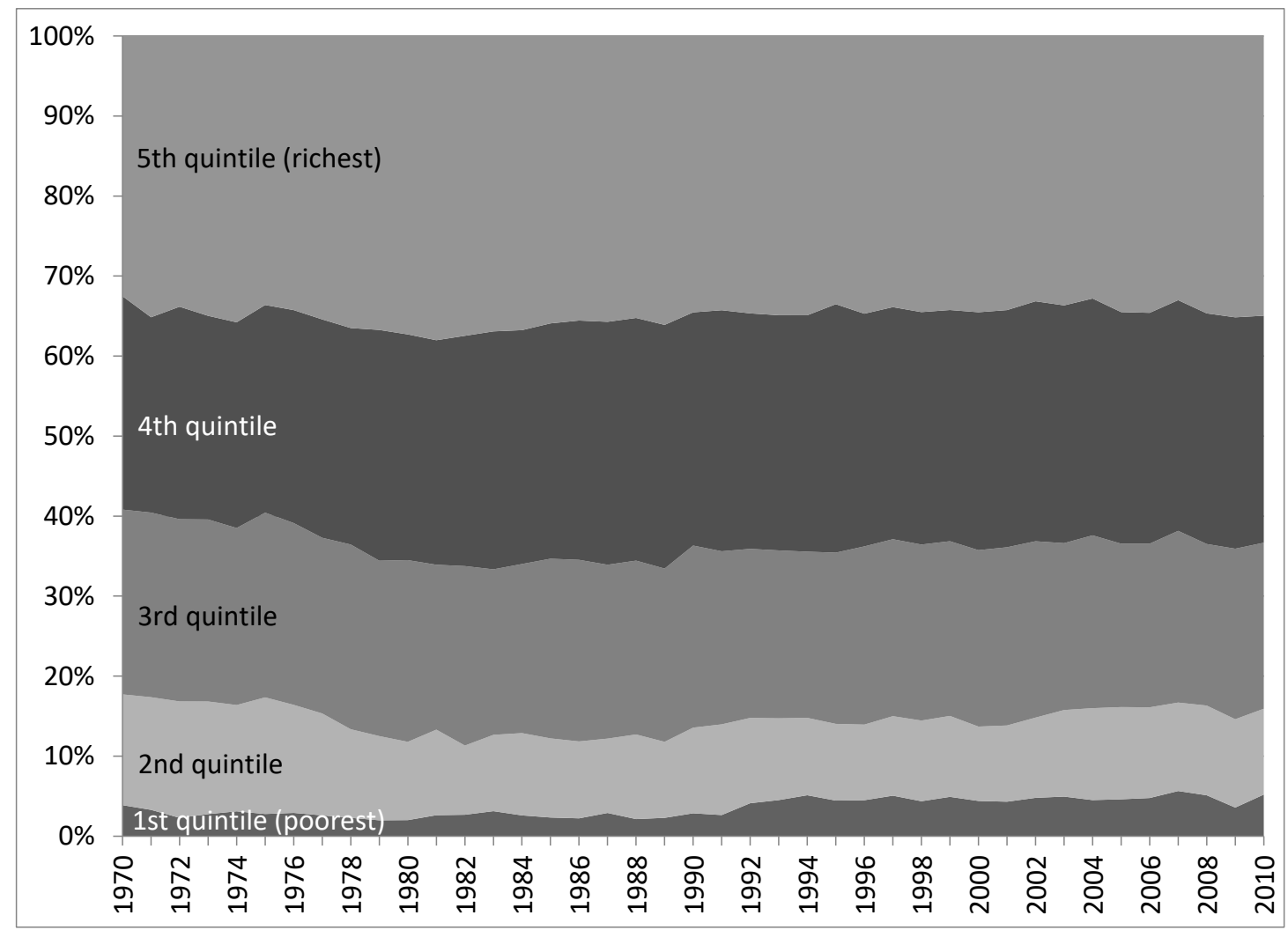

Outright owners are drawn from across the income spectrum, but with some trends over time observable. There was a slight trend away from the households with the highest incomes over the period studied. In terms of those on the lowest incomes, there is significant decrease between 1970 (23 per cent) and 1985 (10 per cent), with a partial reversal of this trend by 2010 (17 per cent).

FIGURE 8 


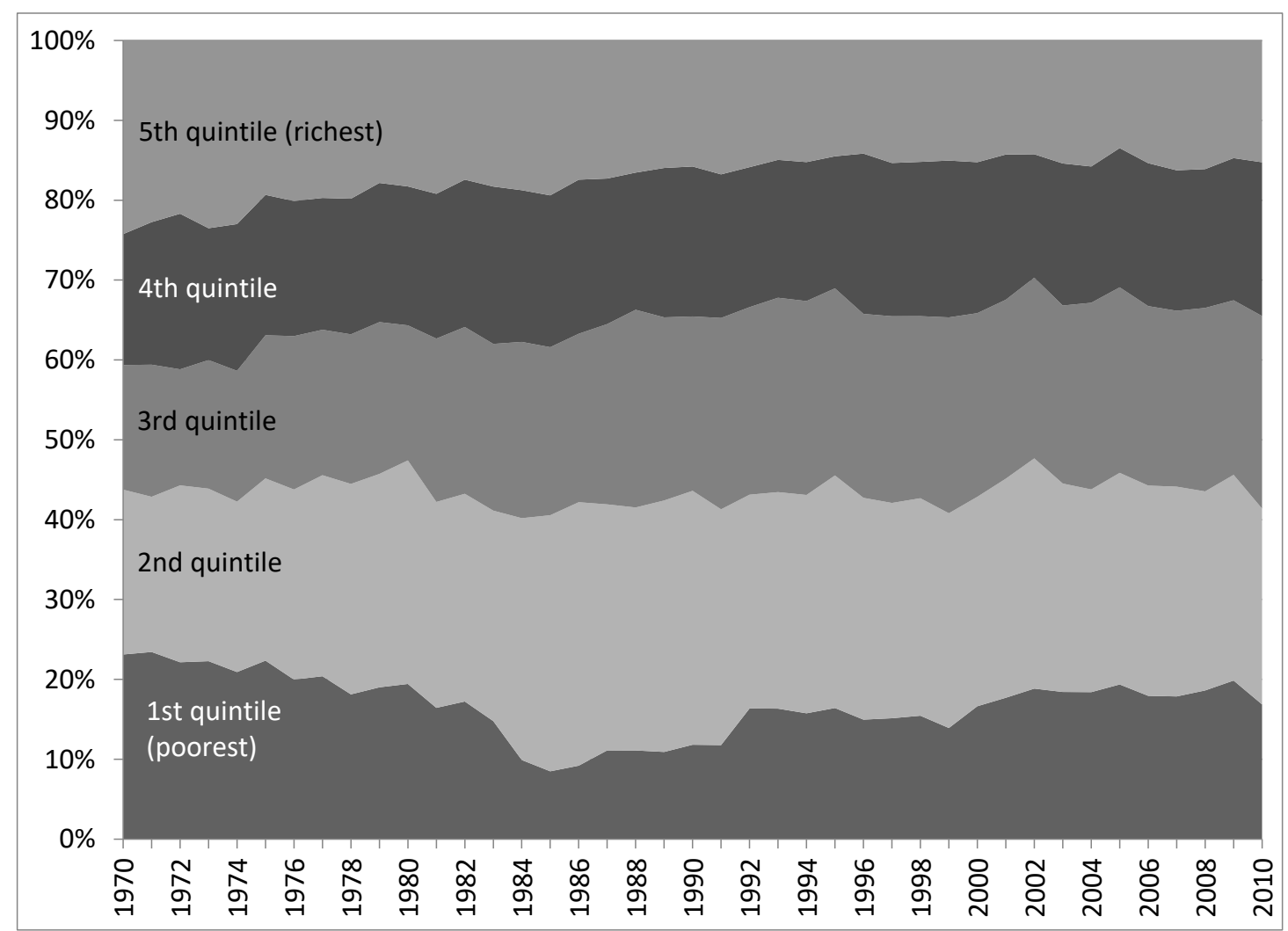

Private rented housing has shown more year-on-year fluctuation than the other two tenures (although this is probably a statistical artefact due to the smaller sample size), but the overall proportions has remained relatively constant (Figure 9). The tenure accommodates households with a wide range of incomes, but with a slightly higher proportion of low earners (around 30 per cent are in the bottom 20 per cent of earners).

\section{FIGURE 9}




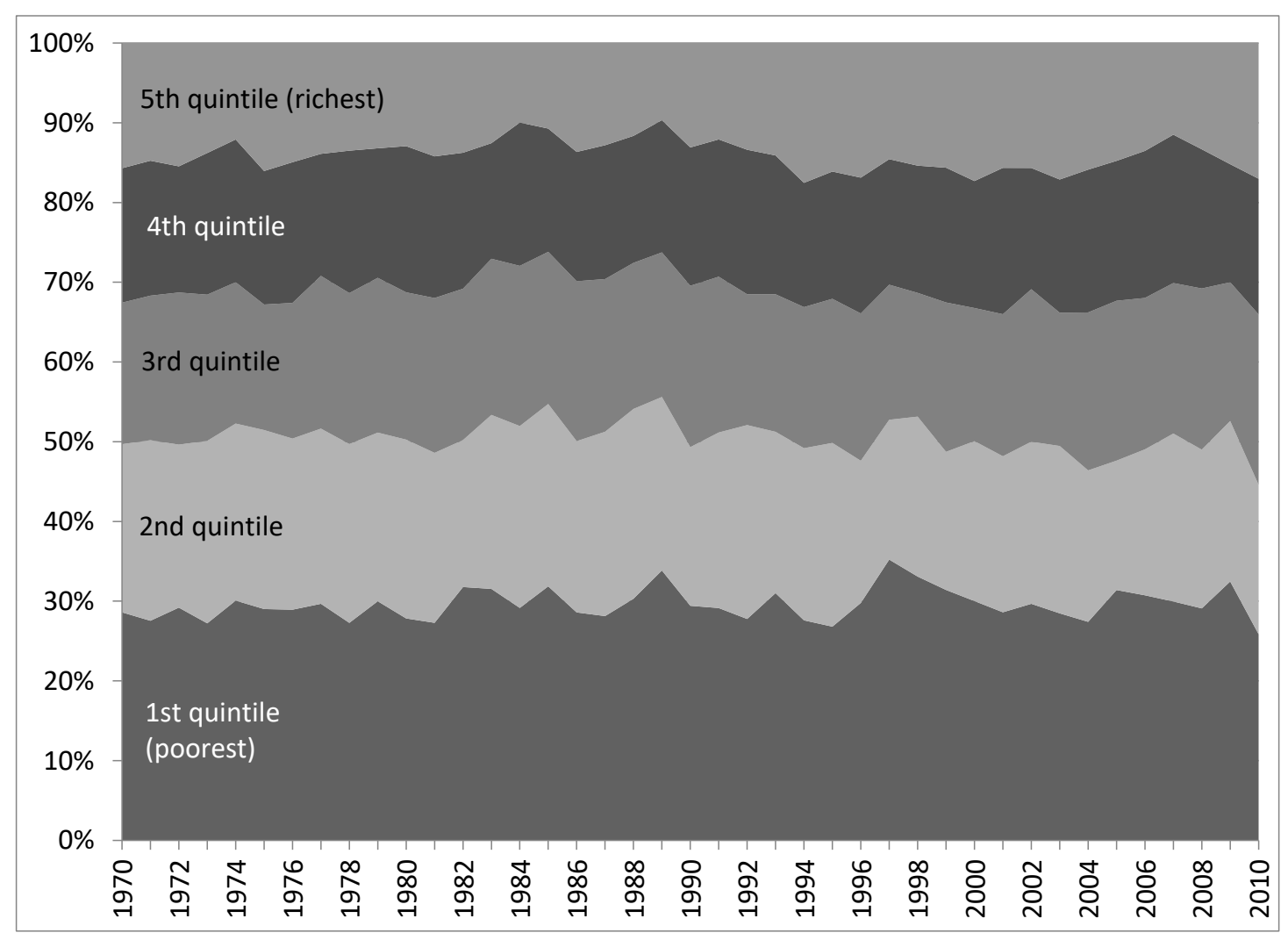

The figures above offer useful insights into each of the tenures, but it is difficult from these alone to be clear about the extent of residualisation or to make effective comparisons between the tenures. The Index of Residualisation calculations enable this analysis. Figure 10 shows the extent of residualisation for each tenure between 1970 and 2008, calculated using the Index. For social housing, there is increasing residualisation over the period. From being a fairly mixed-income tenure in 1970, residualisation is quite rapid, increasing in pace after 1980 (probably linked to the introduction of the Right to Buy), reaching a level of around 0.5, more than three times the value in 1970.

However, since 1991 the Index value has remained at this level, indicating that residualisation is not the significant driving force in the tenure that it once was. This is in line with other research suggesting that the peak period of residualisation has passed (e.g. Lee and Murie, 1997; Murie, 2006). This plateau is interesting because this has occurred in spite of continuing pressures from various policies. However, the structural changes (labour market restructuring, growth of homeownership, etc) are not as significant as previously, suggesting that policy pressures have had a much less impact on residualisation than structural factors. Furthermore, there are additional factors that offer some explanation for the plateau. First, restricted access to social housing means that many low-income households remain in the private rented sector, limiting how far the sector can further residualise. Second, a significant 
number of higher-income social tenants remain in the sector, either by choice or constraint. Third, the expansion of owner occupation has meant that even households on low incomes, have accessed homeownership, reducing the pool of poorer households seeking to access social housing. Research has found that around half of those living in poverty are homeowners (Burrows \& Wilcox, 2000).

FIGURE 10

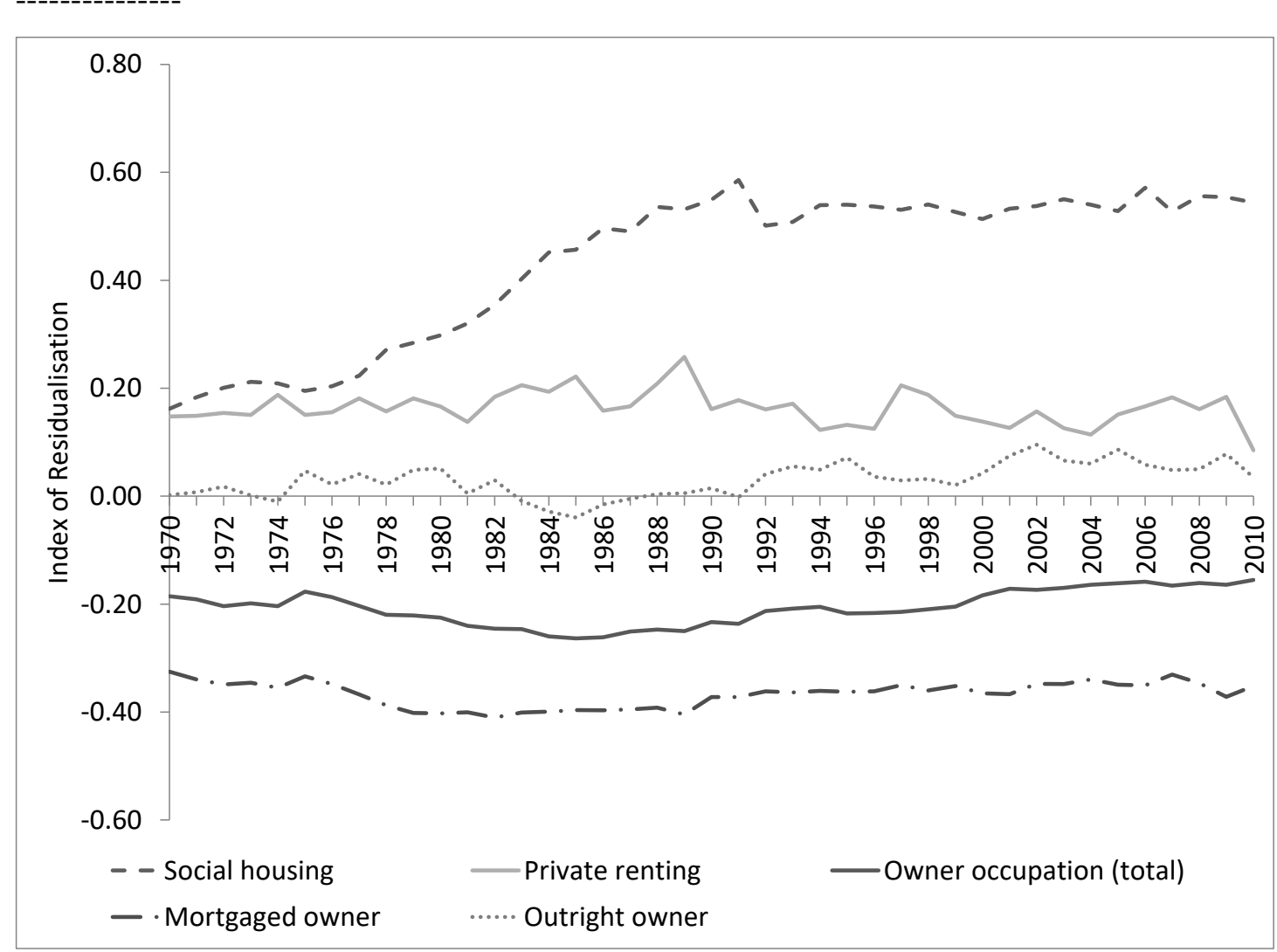

Private rented housing has shown a fairly stable Index figure of 0.15 , indicating a slight preponderance of lower income households, but not a significant one. This reflects the fact that the private rented sector is very diverse, with landlords operating at both the very top and bottom of the housing market. Given the expansion of the sector since the late 1980s, it is interesting that the composition of the sector has not been affected: growth has come from across the income spectrum.

Owner occupation has a slightly preponderance of higher income households, with an average Index value of -0.19 (only slightly greater in magnitude than the value for private renting. This reflects the fact that, with nearly 70 per cent of households in owner occupation, there will be a significant number of lower income households within the sector. However, by 
separating out outright and mortgaged owners, it is possible to see the significant difference between the two groups: the Index value for outright owners fluctuates around 0 to 0.1 (suggesting a very mixed income group), whereas the value for mortgaged owners is -0.3 to 0.4 , indicating a significant preponderance of those on high incomes.

\section{Discussion}

Over the last 40 years, social housing has moved from being a tenure with a wide range of incomes to one that is predominantly for households with low incomes. Previous studies have suggested that this trend began even before than the scope of the present data (Bentham, 1986). This research confirms the findings of the previous studies into residualisation and provides new clarity into the course of the changes that have taken place. It also suggests that policy factors have had a limited effect on the characteristics of social housing tenants, emphasising the importance of structural causes of residualisation. Nevertheless policy can have an important role to play, as demonstrated in the acceleration of residualisation following the introduction of the Right to Buy.

\subsection{Use of the Index}

However, the most significant contribution of this research is the development of the Index of Residualisation, which can accurately chart changes in households in different tenures for the purposes of monitoring and comparative analysis. In addition to the data presented here, there is a wide range of ways in which the Index of Residualisation could be used to develop understanding of the changes occurring in social housing.

\subsubsection{Monitoring}

Although residualisation has been static for 20 years, the Coalition Government's recent policy interventions are likely to significantly affect the sector. The Localism Act (2011) removes the automatic granting of tenancies for life to new social tenants, with landlords being able to additionally offer fixed-term tenancies of a short as two years, with the aim of freeing up social housing for those most in need (DCLG, 2010). At the end of a fixed term, households considered no longer to be in need may not have their tenancy renewed. This may mean many better-off tenants leave social housing and find accommodation in the private sector, reducing income variation and increasing residualisation.

The introduction of Affordable Rent (housing provided by social landlords, with rents of up to 80 per cent of market rent) in 2011 may also affect residualisation. It has been suggested that Affordable Rent could be accessible to slightly more affluent households than current social 
tenants (House of Commons Library, 2011). This could create two tiers within social housing, with traditional social housing becoming further residualised, and Affordable Rent being less so. There have also been moves by some local authorities to prioritise working households on waiting lists, to incentivise households to seek work (e.g. Wandsworth Borough Council, 2011; London Borough of Newham Council, 2011), which may further mitigate residualisation. This move has received support from central government (DCLG, 2011b).

Tracking the changing income mix of social tenants using the Index will enable researchers and policymakers to monitor the impact of these changes. Given the potential negative effects of residualisation, it is vital that policy outcomes are monitored. Alongside policy factors, changing demographic and economic pressures may alter the composition of social housing. By monitoring trends, the Index will enable a clearer understanding of how these drivers affect residualisation.

\subsubsection{Comparative research}

The research presented here used the Index for a comparative study of tenure. However the Index has potential for use in other types of comparative research. There are substantial differences between local housing markets, which are likely to affect the nature of social housing in those areas. In areas with high housing costs, social rents represent a far greater discount relative to the market than in areas with low housing costs. Equally, although many areas have long waiting lists, there are areas where there is low demand for social housing. Given these different operating conditions, differences in the profile of social tenants are likely.

The social housing stock is also far from uniform, comprising a wide range of property types in a variety of different neighbourhoods. It has been suggested that not only is social housing the tenure of the poorest households, but that within social housing, the poorest households live in the worst housing and in the worst areas (Pawson \& Kintrea, 2002). By gathering lowlevel income data through techniques such as small area estimation, it would be possible to use the Index to investigate this proposition. Such small-level spatial analysis has been useful in understanding the impact of the Right to Buy on social housing estates (Murie, 2008), any area where the Index could add further value.

Furthermore, despite the variety of different approaches to social housing in Europe residualisation has been identified as a common theme across many countries (Scanlon \& Whitehead, 2007). The Index could be used to compare the social housing in different 
countries, and may provide further insight into which policy, demographic and socioeconomic factors have the greatest impact on residualisation.

\subsection{Evaluating the Index}

The Index provides a novel and precise quantification of residualisation, and is useful for monitoring the impact of policy and social changes, and for comparative research. It is built on established indices, which have important properties and uses, but offers a novel use of their underlying logic. Furthermore it overcomes the limitations of simpler measures (e.g. comparison of median income) by considering the distribution as well as level of income. Sen (1976) noted the importance of such distributional effects in constructing indices to measure phenomena such as poverty. However, residualisation is a complex phenomenon and there are a number of important considerations to make when interpreting the Index.

\subsubsection{Income as a measure of residualisation}

As highlighted above, there are limitations to using income as a proxy for residualisation. As Forrest and Murie (1983) point out, "neither the size of the sector, the quality of the stock, the particular tenant groups nor the specific features of policy are in themselves determining or necessary factors in the residualisation of council housing" (p. 464). However, tenant characteristics, and particularly income, are most commonly used in the literature to identify residualisation and are strongly associated with the change. This highlights the importance of not using the Index in isolation, but in the context of the wider literature on residualisation.

\subsubsection{Income inequality}

Using income distribution to measure residualisation does not take into account the overall level of income inequality in the population. In a society with high levels of inequality, the difference between the richest and poorest deciles will be much higher than in a society with greater equality, but this difference in financial resources will not be reflected in the Index. This is particularly important as the period over which residualisation has occurred is one of widening inequality in the UK (Murie, 2009).

\subsubsection{Tenure size}

The value of the Index for any given tenure is limited by the size of that tenure. As the size of a tenure increases, the maximum possible Index value decreases, as even at its most residualised, a very large tenure must, by definition, house some more affluent households. A better understanding of the Index can therefore be facilitated by calculating the maximum value of the Index for a tenure, given its size. This can then be used as a point of comparison with its actual Index value. For example, in the UK 68 per cent of households are owner 
occupiers; if this tenure was at its most residualised, these households would be the poorest 68 per cent of households. By calculating the Index based on this hypothetical figure, we obtain the maximum residualisation of the tenure: in this case a value of 0.317 (in comparison with the actual value of -0.161 for the tenure).

\subsubsection{Income grouping}

The calculation of the Index using income groupings is an approximation to the true Index value. The broader the groupings, the further the approximation is from the true Index value. In this research, income deciles were used. However, a better approximation would be given using percentiles. The impact on the Index value given by different band widths should be considered when interpreting the Index.

\subsubsection{Measures of income}

Another important consideration is the measure of income used for calculating the Index. This study used gross household income, which was adjusted to account for household size. This adjustment goes some way to assessing the resources available to that household to meet its needs (for which income is a proxy). However, it also ignores the impact of income taxation, which typically places a significantly lower burden on lower-income households.

The impact of housing costs on the disposable incomes of households is another important consideration. The more households spend on housing costs, the less disposable income they will have. Given the housing costs of social housing tenants are on average significantly lower than those of private tenants and mortgaged homeowners, they need a lower income to maintain a similar standard of living. Therefore, using the Index to compare income after housing costs may well reveal a different picture from that of income before housing costs.

In their recent paper, Stephens and van Steen (2011) develop this idea further to calculate the housing resources of different households. They examine the impact on income of taxation, welfare payments, housing costs and economic benefits derived from living in a particular tenure (e.g. capital gains by homeowners) to quantify the resources available to households. They point out that "it is necessary to look beyond income to capture fully the distribution of resources" (p. 1035) and their measure goes some way to quantifying these resources.

The Index would adapt well to use with more complex measures of income and resources such as this, and these would enable a fuller understanding of the level of residualisation. The focus in this research on tracking historical trends meant that less comprehensive data were available, so more basic measures of income were used. However, for other studies, the use of 
the housing resources measure when calculating the Index may provide a clearer picture of residualisation.

\section{Conclusion}

The Index of Residualisation provides a precise and novel presentation of the income distribution of households within tenures. The changes in the profile of households in social housing in the last 40 years have been charted, revealing a three-fold increase in residualisation over the period. Although over the last two decades there has been little increase in residualisation, this may change due to recent policy developments. Given the impact of residualisation, an effective means to monitor the changes that are occurring is vital.

In addition to monitoring the impact of policy, the Index provides data needed to inform evidence-based discussions into the purpose of social housing. The increase in residualisation over the last 40 years has not been the product of a coherent government agenda, but rather has developed in an unsystematic manner, as the result of a variety of different influences, with governments responding to different opportunities presented by the housing market and political context (Malpass \& Victory, 2010).

Social housing today is very different from its initial vision, but its new role has not been clearly articulated. A changing role for social housing is not necessarily undesirable: residualisation has in part been caused by many of the poorest and most vulnerable households moving into social housing from the private rented sector, which has also provided them with security and affordability. However, if a more residual targeted approach is preferred then this must be complemented by an effective strategy to tackle the negative effects of residualisation. If the sector is to be effective both for its tenants, society and the economy as a whole, there needs to be an evidence base to underpin a strategic policy approach. The Index provides an important part of such an evidence base.

\section{Notes}

${ }^{1}$ It should be noted that both Hamnett (1984) and Bentham (1986) refer to socio-tenurial polarisation rather than residualisation per se. However, these to constructs are closely linked, and for the purposes of measurement are instructive for the analysis of measurement. 


\section{References}

Bentham, G. (1986). Socio-tenurial polarization in the United Kingdom, 1953-1983: the income evidence. Urban Studies, 2, 157-162

Berube, A. (2005). Mixed communities in England: a US perspective on evidence and policy prospects. (York: Joseph Rowntree Foundation)

Burnett, J. (1986). A social history of housing 1815-1985. (Cambridge: Cambridge University Press)

Burrows, R. \& Wilcox, S. (2000). Half the poor: home-owners with low incomes. (London: Council of Mortgage Lenders)

Clapham, D. \& McLennan, D. (1983). Residualisation of public housing: a non-issue, Housing Review, Jan-Feb, 9-10

Cole, I. \& Furbey, R. (1994). The Eclipse of Council Housing. (London: Routledge)

Department for Communities and Local Government (2010). Grant Shapps: A fairer future for social housing, Monday 22 November. Retrieved from www.communities.gov.uk/news/newsroom/1775594

Department for Communities and Local Government (2011a). English Housing Survey: Household Report 2009-10. (London: Communities and Local Government Publications)

Department for Communities and Local Government (2011b). Laying the Foundations: A housing strategy for England. (London: Communities and Local Government Publications)

Department for Communities and Local Government (2013a). Housing statistics live table 241: House building: permanent dwellings completed, by tenure, United Kingdom historical calendar year series. Retrieved from www.gov.uk/government/uploads/system/uploads/attachment_data/file/86136/LiveTable241. $\underline{\mathrm{xls}}$ 
Department for Communities and Local Government (2013b). Housing statistics live table 671: social housing sales - annual Right to Buy sales for England. Retrieved from www.gov.uk/government/uploads/system/uploads/attachment data/file/200034/Table 671.xls

Department for Communities and Local Government (2013c). Housing statistics live table 801: tenure trend, from 1918. Retrieved from www.communities.gov.uk/documents/housing/xls/141491.xls

Diacon, D., Pattison, B., Strutt, J. \& Vine, J. (2010). Support with housing costs: developing a simplified and sustainable system. (Coalville: Building and Social Housing Foundation)

Flynn, R. (1988). Political acquiescence, privatisation and residualisation in British housing policy. Journal of Social Policy, 17(3), 289-312

Forrest, R. \& Murie, A. (1983). Residualization and council housing: aspects of the changing social relations of housing tenure. Journal of Social Policy, 12, 453-468

Forrest, R. \& Murie, A. (1988). Selling the welfare state: the privatisation of public housing. (Worcester: Routledge)

Hamnett, C. (1984) Housing the two nations: socio-tenurial polarization in England and Wales, 1961-81. Urban Studies, 43, 389-405

Harloe, M. (1978) The green paper on housing policy. (In M. Brown \& S. Baldwin (Eds.), The year book of social policy in Britain 1977 (pp. 3-21). London: Routledge and Kegan Paul.)

Hills, J. (2007). Ends and means: the future roles of social housing in England. (London: LSE London)

Homes and Communities Agency (n.d.). National Affordable Housing Programme. Retrieved from www.homesandcommunities.co.uk/ourwork/national-affordable-housing-programme and Affordable Homes Programme. Retrieved from www.homesandcommunities.co.uk/affordable-homes

House of Commons Library (2011). Affordable Rent model. (London: House of Commons Library) 
Lee, P. and Murie, A. (1997). Poverty, housing tenure and social exclusion. (Bristol: Policy Press)

London Borough of Newham (2011) Review of Housing Allocations Policy. Retrieved from mgov.newham.gov.uk/mgConvert2PDF.aspx?ID=44409

Lupton, R., Tunstall, R., Sigle-Rushton, W., Obolenskaya, P., Sabates, R., Meschi, E., Kneale, D. \& Salter, E. (2009). Growing up in social housing: a profile of four generations, 1946 to the present day. (London: Tenant Services Authority)

Malpass, P. \& Murie, A. (1982). Housing policy and practice. (London: Macmillan)

Malpass, P. \& Victory, C. (2010). The modernisation of social housing in England. International Journal of Housing Policy, 10(1), 3-18

Malpass, P. (1983). Residualisation and the restructuring of housing tenure, Housing Review, Mar-Apr, 44-45

Malpass, P. (1990). Reshaping housing policy: subsidies, rents and residualisation. (London: Routledge)

Mullins, D. \& Murie, A. (2006). Housing policy in the UK. (Basingstoke: Palgrave Macmillan)

Murie, A. (1997). The social rented sector, housing and the welfare state in the UK. Housing Studies, 12(4), 437-461

Murie, A. (2006). Moving with the times: changing frameworks for housing research and policy. (In P. Malpass and L. Cairncross (Eds.) Building on the past (pp. 15-50). Bristol: Policy Press).

Murie, A. (2008). Social housing privatisation in England. (In K. Scanlon \& C. Whitehead (Eds.) Social housing in Europe II: A review of policies and outcomes (pp. 241-259). London: LSE London.) 
Murie, A. (2009). The modernisation of housing in England, Tijdschrift voor Economische en Sociale Geografie, 100(4), 535-548

National Audit Office (2010) The Decent Homes Programme. (London: The Stationery Office)

Office for National Statistics (2013a). Family Expenditure Survey, 1970-2000. (Colchester, Essex: UK Data Archive)

Office for National Statistics and Department for Environment, Food and Rural Affairs (2013b). Expenditure and Food Survey, 2001-2007. (Colchester, Essex: UK Data Archive)

Office for National Statistics, Social and Vital Statistics Division (2013c). Living Costs and Food Survey, 2008-2010. (Colchester, Essex: UK Data Archive)

Pawson, H. \& Kintrea, K. (2002). Part of the problem or part of the solution? Social housing allocation policies and social exclusion in Britain, Journal of Social Policy, 31(4), 643-647

Scanlon, K. \& Whitehead, C. (2007). Social Housing in Europe. (London: LSE London.)

Sen, A. (1976) An ordinal approach to measurement, Econometrica, 44 (2), 219-231.

Stephens, M. \& van Steen, G. (2011). 'Housing Poverty' and Income Poverty in England and The Netherlands. Housing Studies, 26(7-8), 1035-1057

Suits, D. B. (1977). Measurement of tax progressivity. American Economic Review, 67(4), $747-752$

Torgersen, U. (1987). Housing: the wobbly pillar under the welfare state. (In B. Turner, J. Kemeny \& L. Lundqvist (Eds.) Between state and market: housing in the post-industrial era (pp. 116-126). Stockholm: Almqvist and Wiksell.)

Wandsworth Borough Council (2011). Councillors back housing into work pilot, Thursday 24 November. Retrieved from www.wandsworth.gov.uk/news/article/10857/councillors_back_housing_into_work_pilot 


\section{Figures}

FIGURE 1: Tenure trend: percentage of households by tenure, England, 1971-2010 Source: DCLG, 2011a, 2013c

FIGURE 2: Gini coefficient

FIGURE 3: Suits Index of tax progressivity

FIGURE 4: Comparison of the household incomes of a population and sub-population

FIGURE 5: Income profile of social housing tenants

FIGURE 6: Income profile of owner occupiers

FIGURE 7: Income profile of mortgaged owner occupiers

FIGURE 8: Income profile of outright owner occupiers

FIGURE 9: Income profile of private tenants

FIGURE 10: Index of Residualisation by tenure 